\title{
OPTIMIZATION OF INJECTION MOULDING PROCESS TO ACHIEVE LEAST CYCLE TIME AT LEAST COST FOR A PART USING MOULD FLOW ANALYSIS
}

\author{
NAVJOT. C. ACHARYA \\ Student Scholar, Department of Mechanical Engineering, Y.C.C.E, Nagpur, India ${ }^{1}$
}

\begin{abstract}
Injection moulding is a process of manufacturing plastic product. A mould is prepared which consists of cavity, core and ejection system. The molten plastic material is fed in the mould and takes the form of cavity present in the mould. This paper presents the flow analysis (CFD) of a part using Solid works 2020 which is to be produced using injection moulding to optimize the process. The different parameters to optimize the process are cycle time which consists of filling time, cooling time, ejection time and mould opening and closing time; injection pressure; material melting temperature; material viscosity and type of mould. The attempt is made to complete the process in the least possible time subjected to practical and cost related constraints like max clamping force should not exceed 100 tonne to save the cost of machine.
\end{abstract}

Index Terms: - Filling time, Cooling time, 2 plate mould, 3 plate mould, sprue, runner, gate, venting, Viscosity, register ring, sprue bush, sprue, cavity plate, cavity back plate, guide pillar, guide bush, core insert, core plate, spacer, ejector plate, ejector pins, ejector back plate, return pin, rest button.

\section{Introduction}

As shown in the figure 1 , a basic 2 plate mould consists of register ring, sprue bush, sprue, cavity plate, cavity back plate, guide pillar, guide bush, core insert, core plate, spacer, ejector plate, ejector pins, ejector back plate, return pin, rest button and bottom plate.

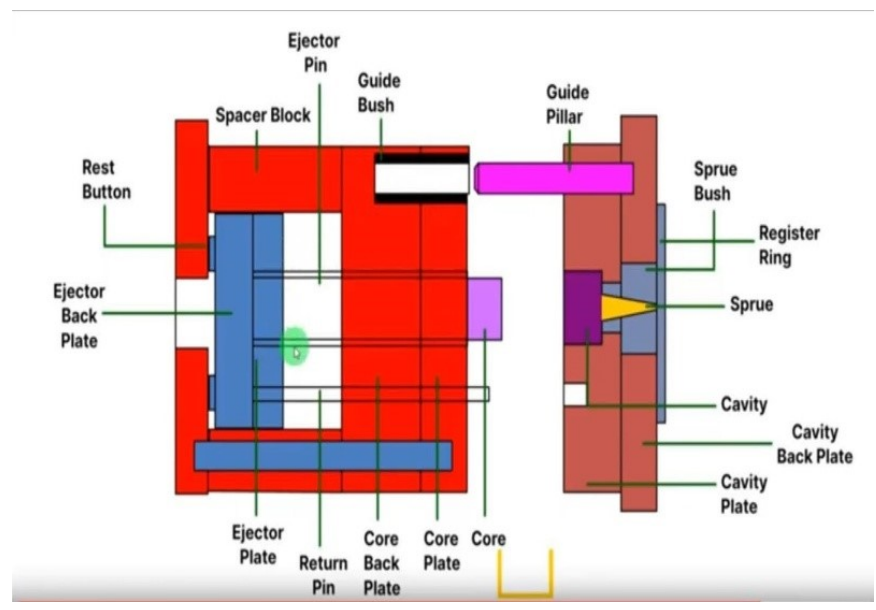

Fig 1:- showing Mould components of a 2 plate mould

The disadvantage of a 2 plate mould is that the final part produced consists of sprue, runners and gate which needs to be separated from the part by machining which will consume lot of time.

To overcome this, an extra plate called runner plate is added between cavity plate and cavity back plate which consists of runners and gates. When the mould opens for part ejection the part is separated from the runner plate hence this way the runner, gate and sprue is separated from the part and no machining is required.

\section{Objectives}

This research paper aims to calculate the optimum injection pressure, filling time and flow rate subjected to constraint that the maximum clamping force must not exceed 100 tonne as the cost of machine would exceed resulting in increase of process cost. Hence this research paper aims to optimize the injection moulding process to achieve least cycle time at least cost.

\section{Methodology / Process}




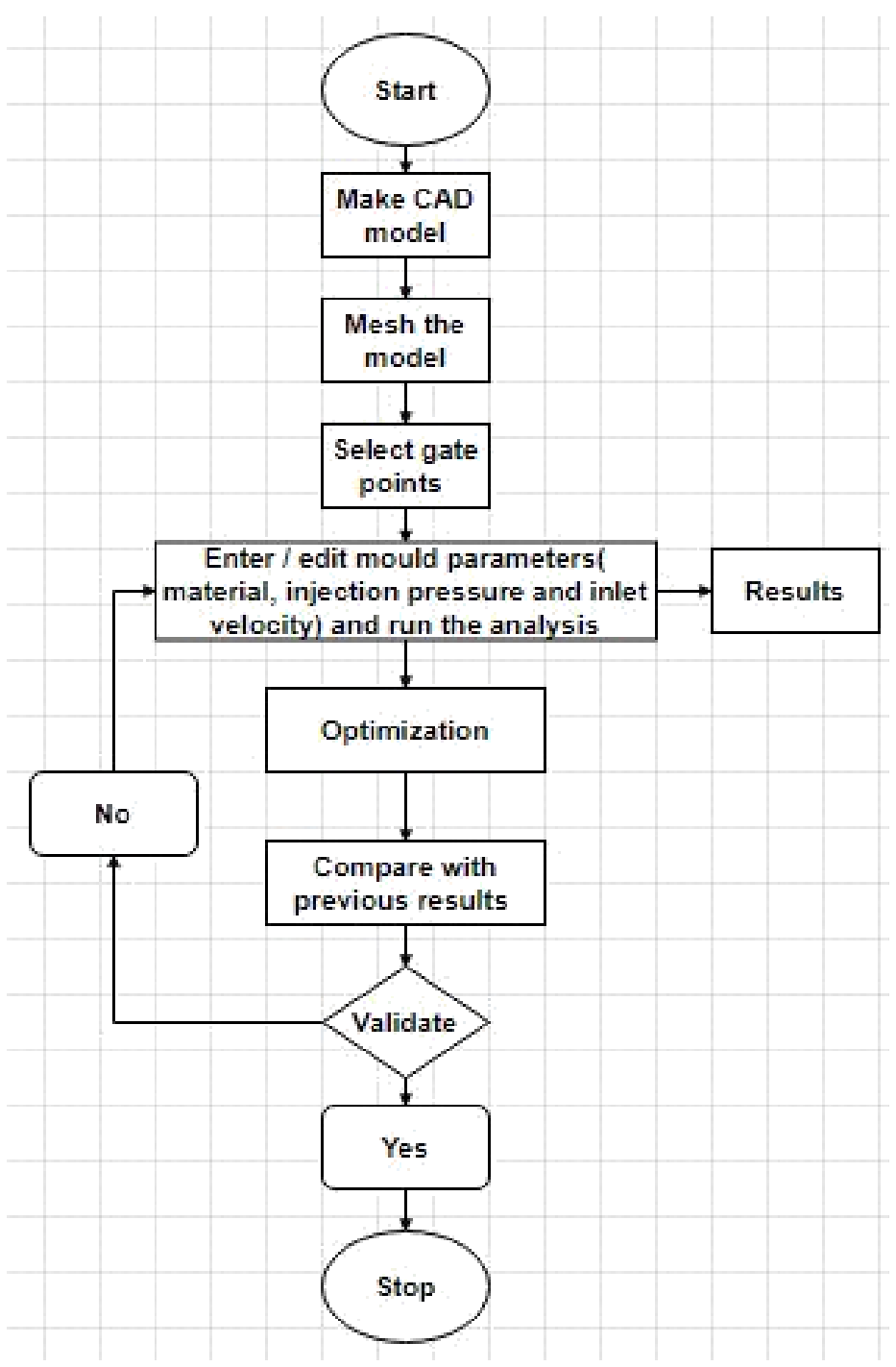

Fig 2:- showing the methodology / process

\section{Data for analysis}

\subsection{CAD data}

The CAD model is prepared in solid works 2020 as shown in figure 3 . The gate points are chosen in such a way that the material distribution should be uniform throughout the volume. Hence 4 inlet gate points are taken for the CFD analysis as shown in the figure 3.

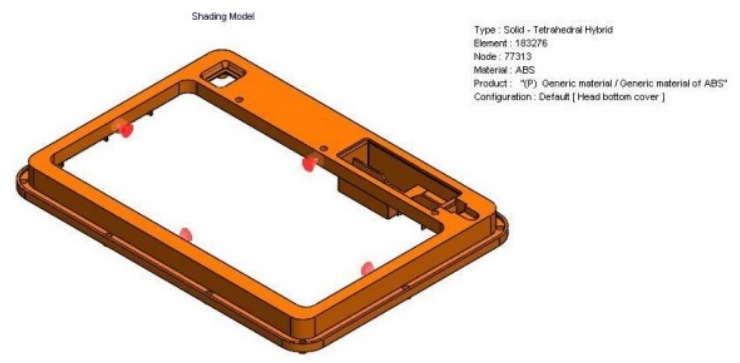

Fig 3: - Cad model

\subsection{FEM data}

The FEM model is created by meshing the CAD model using solid tetrahedral hybrid element in solid works 2020. The mesh model is shown in the figure 4 and the number of elements and nodes are described in the table 1 below.

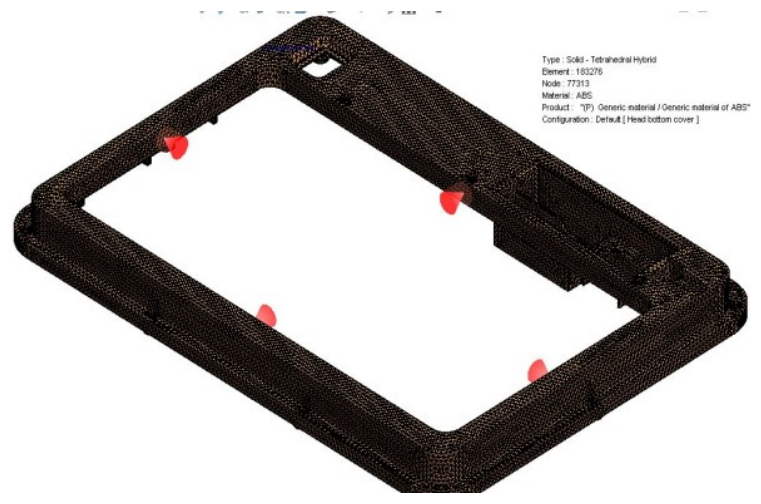

Fig 4: - Meshed model

Table 1: - Element data.

\begin{tabular}{|l|l|}
\hline lement type & $\begin{array}{l}\text { olid } \\
\text { ybrid }\end{array} \quad$ tetrahedral \\
\hline Jo. of elements & 83276 \\
\hline Jo. of nodes & 7313 \\
\hline
\end{tabular}

\subsection{Material properties}

The material selected is ABS (acrilonitrile butadlene styrene). The phase of the material will change from solid to liquid and the properties will also change accordingly. The variation of the different properties of material with temperature is shown below in the figures 5, 6,7 and 8 .

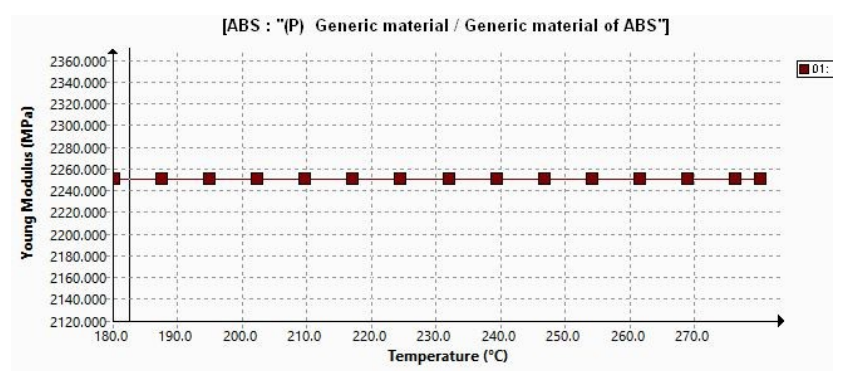

Fig 5: - variation of young's modulus with temperature 


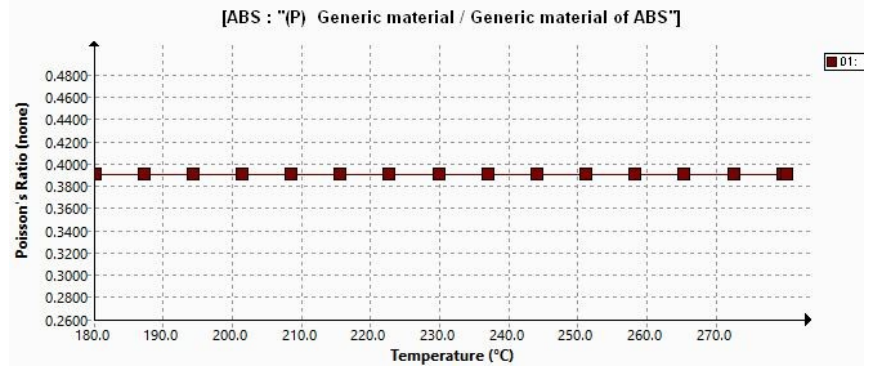

Fig 6: - Variation of poison's ration with temperature

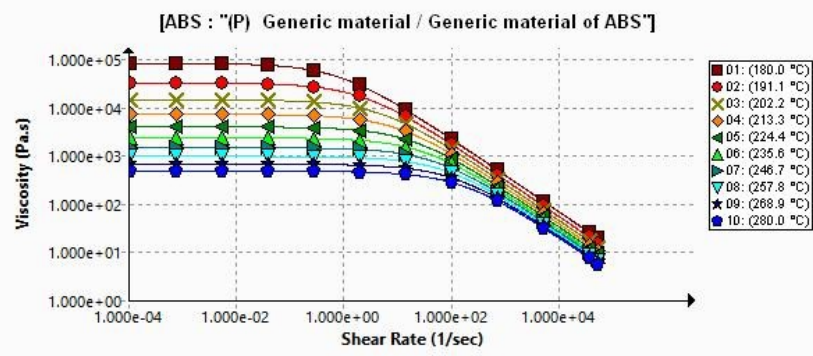

Fig 7:- Variation of viscosity with the temperature

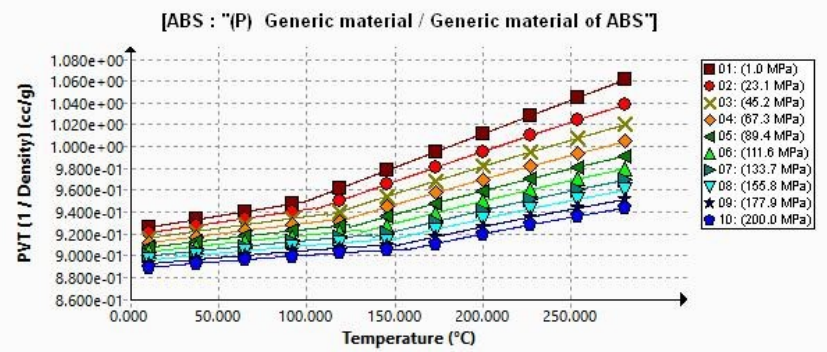

Fig 8: - Variation of specific volume with temperature

\subsection{Process parameters}

To achieve the optimization at the least cost the clamping force was limited to 100 tonne so as to reduce the cost of machine and iterations were carried out for the pressures ranging from $50 \mathrm{MPa}$ to $150 \mathrm{MPa}$, hence the limiting pressure is taken as $150 \mathrm{MPa}$, as shown in figure 9 , so as to find out the exact pressure between this range which can be used for injection.

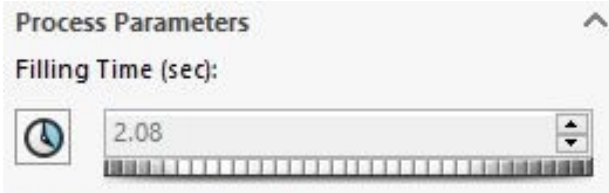

Melt Temperature $\left({ }^{\circ} \mathrm{C}\right)$ :

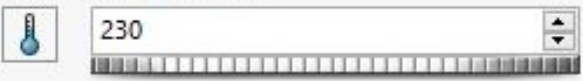

Mold Temperature $\left({ }^{\circ} \mathrm{C}\right)$ :

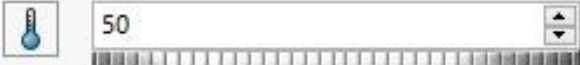

Injection Pressure Limit (MPa):

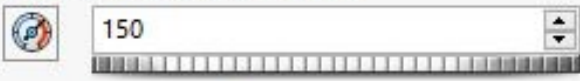

Clamp Force Limit (Tonne):

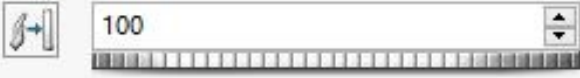

Fig 9: - Process parameter data

\section{Simulation Results}

\subsection{Filling time result}

The fill time is $1.7 \mathrm{sec}$ as shown in the figure 10 below. The filling time is max at the places far away from the gate point location.

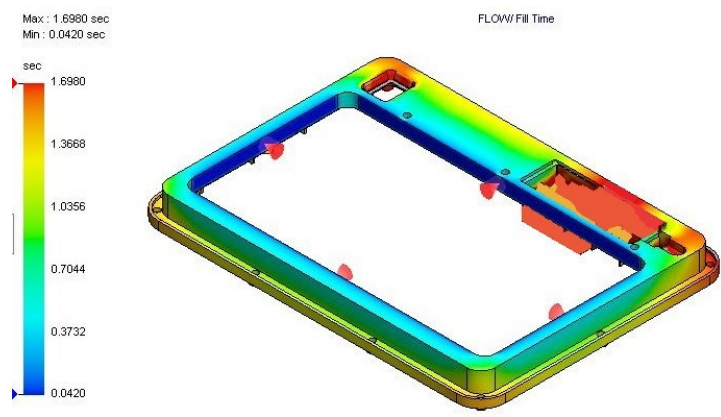

Fig 10: - Filling time

\subsection{Injection pressure result}

The maximum injection pressure obtained is $89 \mathrm{Mpa}$ as shown in figure 11. Since the maximum pressure developed at the end of fill is 89 MPA so that clamping force should not exceed 100 tonne, the injection pressure must be equal to or greater than 89 MPA. The pressure in the mould will vary with respect to time and will be max at the end of fill as shown in the figure 12 . 

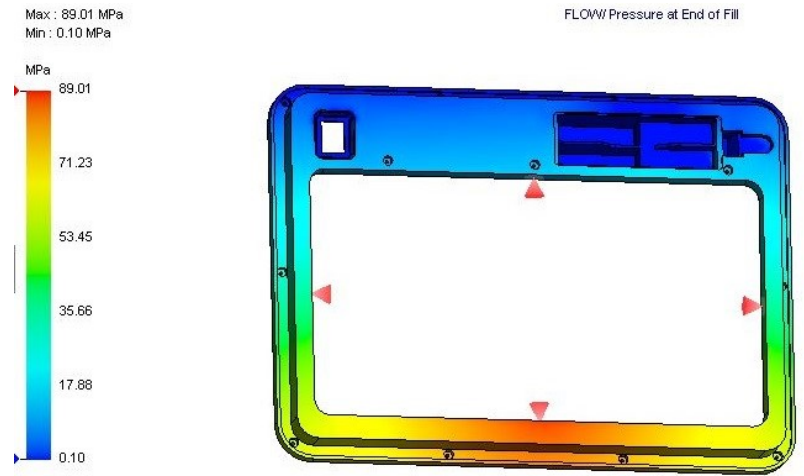

Fig 11: - Pressure at end of fill.

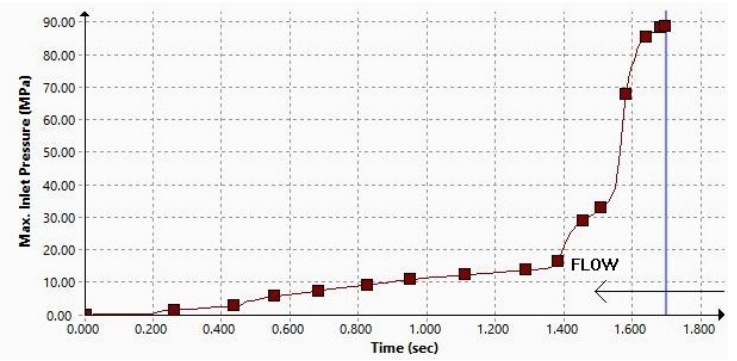

Fig 12: - Variation of max inlet pressure with time

\subsection{Clamping force}

At optimum injection pressure the clamping force developed is 95.1 tonne as shown in figure 13 which is less than 100 tonne.

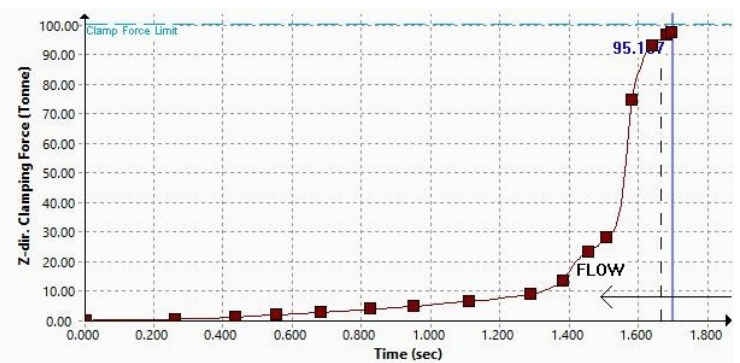

Fig 13: - Variation of clamping force with time

\subsection{Flow Analysis}

The flow rate at the time of filling varies with respect to time as shown in figure 14 due to unevenness in the model and the maximum flow rate is $97 \mathrm{cc} / \mathrm{s}$.

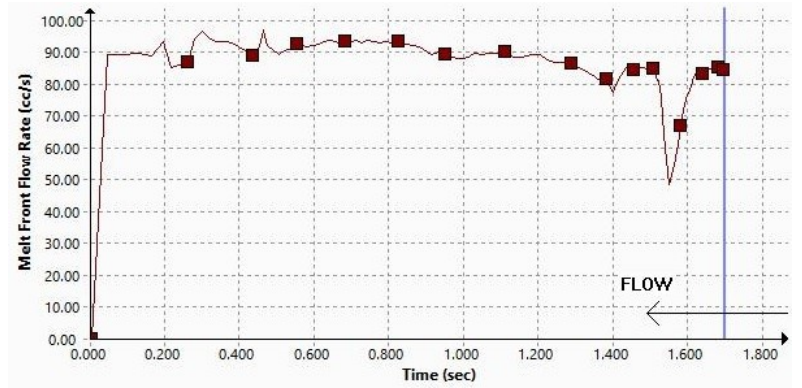

Fig 14: - Variation of Flow rate with respect to time

\subsection{Cycle time}

The cooling time obtained from the analysis is $2.3 \mathrm{sec}$; filling time obtained is $1.7 \mathrm{sec}$, mould opening and closing time is $8 \mathrm{sec}$ and ejection time is $3 \mathrm{sec}$. Hence the cycle time is $15 \mathrm{sec}$.

\section{Conclusions}

The summary of the results are shown in the table 2 below.

Table 2: - Summary of result

\begin{tabular}{|l|l|}
\hline Filling time & $1.7 \mathrm{sec}$ \\
\hline Injection pressure & $89 \mathrm{MPa}$ \\
\hline Clamping force & $95.1 \mathrm{Tonne}$ \\
\hline Flow rate & $97 \mathrm{cc} / \mathrm{s}$ \\
\hline Cycle time & $15 \mathrm{sec}$ \\
\hline
\end{tabular}

It is concluded that the optimum injection pressure and cycle time is obtained by performing rigorous iterations where the range of pressure was set between $50 \mathrm{MPa}$ to $150 \mathrm{MPa}$ and the optimum pressure obtained is $89 \mathrm{MPa}$ with least filling time of $1.7 \mathrm{sec}$. If the injection pressure is increased beyond $89 \mathrm{MPa}$ the clamping force increases beyond 100 Tonne which is not desired.

\section{References}

[1] Injection moulding methods design, optimization, simulation of plastic toy building block by mould flow analysis - IJMET 2015.

[2] A Brief Review on injection moulding manufacturing process - ELSEVIER March 2016.

[3] Design and optimisation of conformal cooling channels in injection moulding tools - ELSEVIER May 2005.

[4] Process parameters optimization of injection moulding using a fast strip analysis as a surrogate model IJAMT Aug 2010. 
[5] Multi Response optimization of injection moulding Process parameters to reduce cycle time and warpage - ELSEVIER Jan 2018.

[6] Akbarzadeh Tootoonchi, A. International Journal of Modeling and Optimization,(2011).

[7] Huszar, M., Belblidia, F., Davies, H. M., Arnold, C., Bould, D., \& Sienz, J." Sustainable Materials and Technologies, 5(2015)., 1-8. 